\title{
PHYSICAL PROTECTION IMPLEMENTATION IN THE FORMER SOVIET UNION
}

\author{
James D. Williams \\ Sandia National Laboratories \\ P. O. Box 5800 MS0765 \\ Albuquerque, NM 87185-0765 \\ 505-845-8766 jdwilli@sandia.gov
}

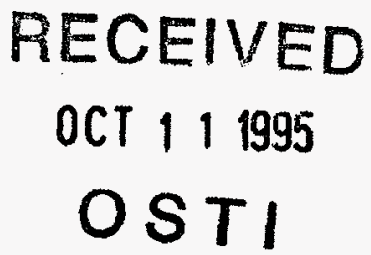

\begin{abstract}
This paper presents an overview of the physical protection cooperation activities between Sandia National Laboratories and the countries of the Former Soviet Union (FSU) regarding nuclear Material Protection, Control, and Accounting (MPC\&A) responsibilities.
\end{abstract}

Begun approximately four years ago as part of the Safe, Secure Dismantlement Program, this project is intended to reduce proliferation of weapons of mass destruction. The purpose of the program is to accelerate progress toward a goal shared by both the FSU countries and the United States: to reduce the risk of nuclear weapons proliferation, including such threats as theft, diversion, and unauthorized possession of nuclear materials. This will be accomplished by strengthening the MPC\&A systems in the United States and the FSU countries. This program, known as the Government-to-Government Program, is sponsored by US Senators Nunn and Lugar and is complemented by the US Department of Energy Laboratory-to-Laboratory MPC\&A Program.

US and FSU representatives exchange visits and discuss physical protection philosophies. FSU representatives have received formal training in the US process of system design and analysis to include the design of an effective physical protection system, the determination of physical protection system objectives, the initial design of a physical protection system, the evaluation of the design, and oftentimes, a redesign or refinement of the existing system.

This work was supported by the U.S. Department of Energy under Contract DE-AC04-94Al85000.
Some FSU facilities have philosophies very similar to those of the United States, but when they differ, the US and FSU countries' representatives must negotiate until suitable solutions are reached. Other FSU facilities, because of their heavy reliance on guard forces, have not developed a systematic design process.

Cooperative work between US national laboratories and their FSU counterparts has thus far resulted in major physical protection enhancements at several FSU facilities.

\section{INTRODUCTION}

The first discussions of cooperation on Material Protection Control and Accounting (MPC\&A) between the United States and the Former Soviet Union (FSU) began approximately four years ago as part of the Safe, Secure Dismantlement (SSD) Program (also known as the Cooperative Threat Reduction Program or the Nunn-Lugar Program after its sponsors in the US Senate).

Some other programs under the SSD Program are armored blankets, improved railcars, and the design of an underground storage facility. Additionally, the Government-to-Government agreement was established in 1993 to develop cooperation for upgrading MPC\&A capabilities for key FSU facilities.

At a January 1994 summit meeting in Moscow, Presidents Clinton and Yeltsin stressed the "high priority" and "great significance" of joint work on MPC\&A as part of the cooperative effort between Russia and the United States to reduce proliferation of weapons of mass destruction. Other Governmentto-Government interactions related to MPC\&A 


\section{DISCLAIMER}

Portions of this document may be illegible in electronic image products. Images are produced from the best available original document. 
include programs to establish national systems of MPC\&A in the other FSU countries.

In April 1994, Under Secretary of Energy Charles Curtis directed the DOE national laboratories to initiate a new program of cooperation with the Russian Federation's nuclear institutes. The purpose of the program is to accelerate progress toward a goal shared by both Russia and the United States to reduce the risks of nuclear weapons proliferation, including such threats as theft, diversion, and unauthorized possession of nuclear materials by strengthening MPC\&A systems in both countries. This new program is called the Laboratory-to-Laboratory MPC\&A program and is designed to complement Government-to-Government programs.

Sandia National Laboratories (SNL) plays a primary role for physical protection, and Los Alamos National Laboratory (LANL) plays a primary role for material control and accounting. SNL and LANL work in conjunction with other national laboratories in conducting these programs. In particular, Agronne National Laboratory is heavily involved in the physical protection efforts in Kazakhstan and Ukraine.

The reliance on guards and the lack of resources for upgrading and maintaining existing systems have created a need for major improvements in physical protection at many FSU facilities. Although guard force security has adequately protected facilities in the past, increased labor costs and reduced military support are expected to create a greater reliance on hardware-based systems.

\section{PHYSICAL PROTECTION AT FSU FACILITIES}

The implementation of physical protection systems at FSU facilities are planned in cooperation with site personnel.

One of SNL's roles in the Government-toGovernment MPC\&A program with the FSU countries is to provide expertise in the area of facility physical protection of nuclear materials. Facility physical protection is in itself a component of the broad outline by the Government-to-Government MPC\&A program. The physical protection process involves determining system requirements, designing a system, evaluating the system, and then redesigning, if necessary before implementation. SNL's mission under the general MPC\&A program is to apply its expertise in the following areas:
- Facility and/or site characterization, including design basis threat development work. Design basis threat development addresses the threat to a particular facility and the resultant facility protection system.

- The site characterization is followed by a complete physical protection system design, analysis, implementation, and evaluation for components of the physical protection including:

- Perimeter barriers and sensors

- Video assessment systems

- Interior sensor systems

- Information control and display systems

- Item protection and monitoring systems

- Communication and event response systems.

The fully functional system also includes training for the supporting activities and maintenance.

The design and analysis process is illustrated in Figure 1 for the total MPC\&A process of integrating physical protection and material control and accountability. Figure 2 shows the physical protection portion of the process.

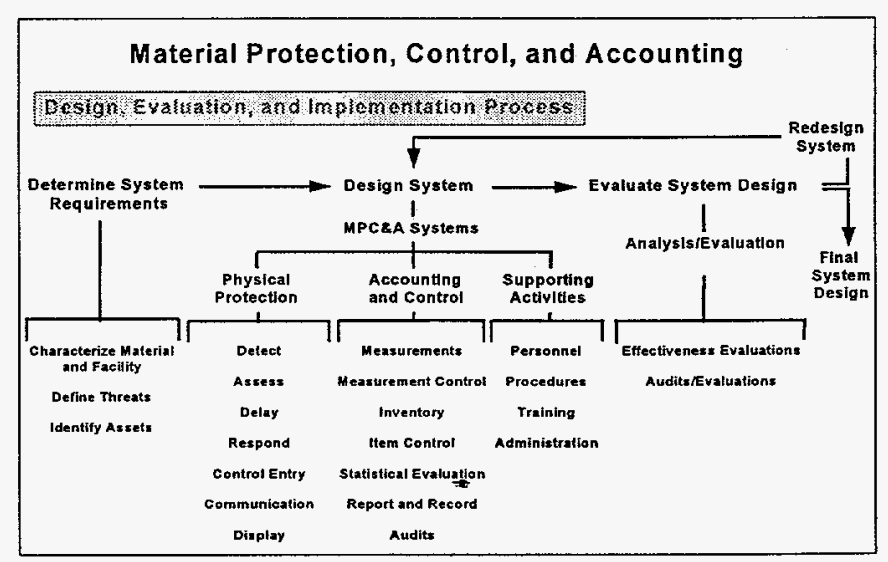

Figure 1. MPC\&A Design Evaluation and Implementation Process 


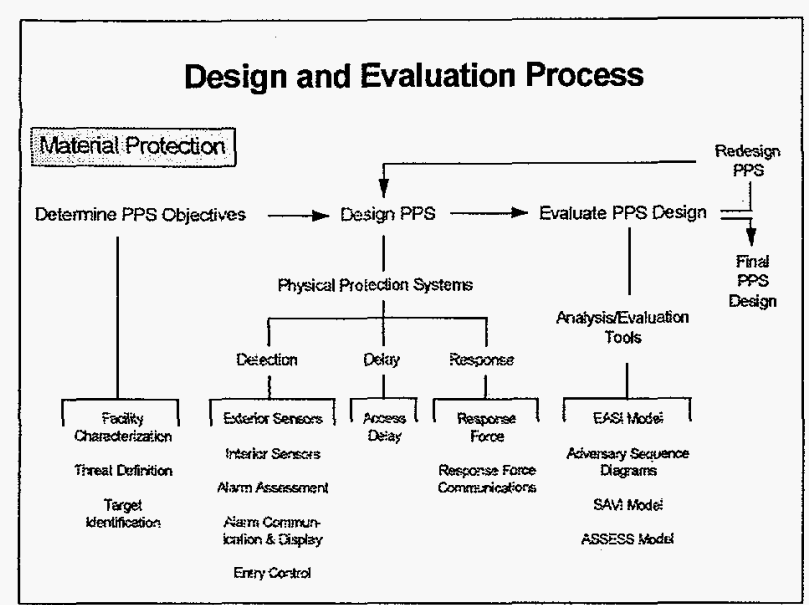

Figure 2. Material Protection Design and Evaluation Process

FSU facilities and institutes and the US DOE national laboratories, under the MPC\&A programs, are sharing experience and technical expertise through "hands-on" demonstrations of capabilities. Several sites are a proving ground for the expansion of MPC\&A activities to other institutes and sites within the FSU's nuclear infrastructure. As such, their success - and the success of similar activities at other important installations - will help determine the speed and effectiveness with which the Governmentto-Government program can build and maintain the best possible assurance for the protection, control, and accounting of nuclear materials in the FSU countries and the United States.

Recent work on a physical protection system at a FSU facility embodied the real-life nature of the Government-to-Government cooperative effort. Not only has the joint US/FSU design and implementation of this physical protection system demonstrated a significant and immediate improvement in the MPC\&A of this important facility, it has enhanced the confidence between US laboratories and other FSU facilities.

\section{Physical Protection System Implementation}

The physical protection system designs for these facilities consists, in general, of four main components: physical barriers, entry control systems, alarm assessment systems, and interior and exterior sensors. These systems constitute the real-life capabilities implied between physical protection design (including alarm assessment) and alarm communication and display.

\section{Exterior Detection and Assessment}

The exterior detection and assessment system at many FSU sites consists of one or more singletechnology sensors. In general, alarm assessment is performed by guards. The systems are poorly maintained and have considerable vegetation encroachment (Figure 3).

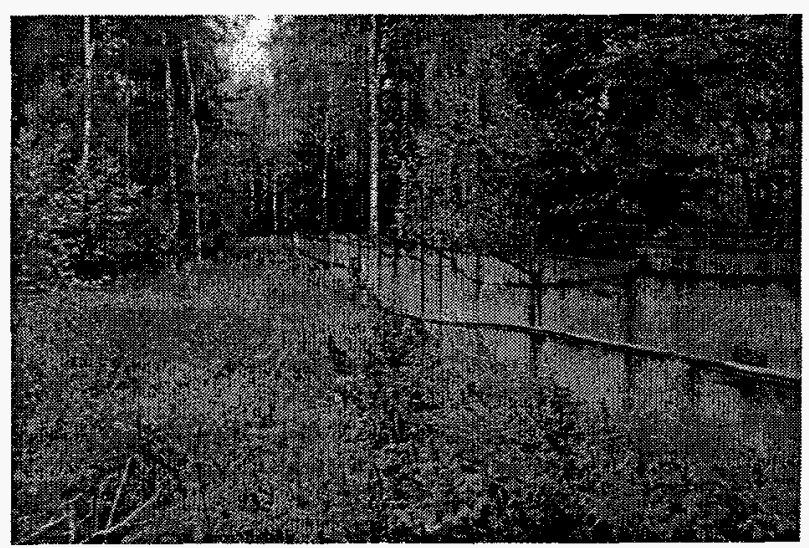

Figure 3. Site with vegetation encroachment.

\section{Interior Detection and Assessment}

The interior detection and assessment system is also a single-technology system and has no closedcircuit television (CCTV) assessment. Open wiring and the lack of tamper protection and linesupervision render it susceptible to insider defeat.

\section{Information Control and Display Systems}

Many of the existing sites still rely on mechanical counter annunciators (Figure 4). They were manufactured before the advent of computers in annunciation systems and do not provide maps or alarm locations.

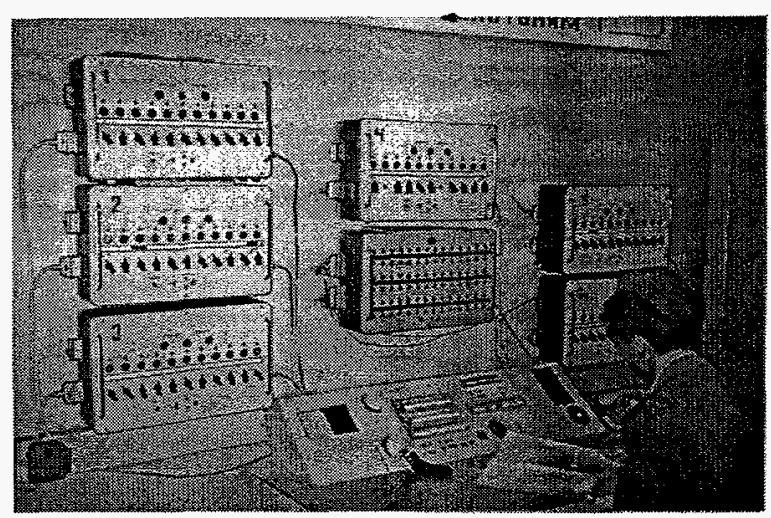

Figure 4. Mechanical counter annunciator 


\section{Site Preparation}

Before physical protection systems can be implemented, the site must be prepared. At many FSU facilities, this preparation includes considerable grounds cleanup. Brush, discarded objects and debris, and existing fences must be removed and trees must be trimmed. This results in a clear zone around the buildings (Figure 5) and greatly facilitates the installation of perimeter sensors and fences. It is preferred that there be no trees in the clear zone, but sometimes it is difficult to get permission to remove them. The clear zone-a system design element-will maximize the effectiveness of security cameras and barrier and detection sensors. System design also entails the instal-lation of window barriers, vehicle and personnel gates, and power supply and signal cabling to and from the buildings.

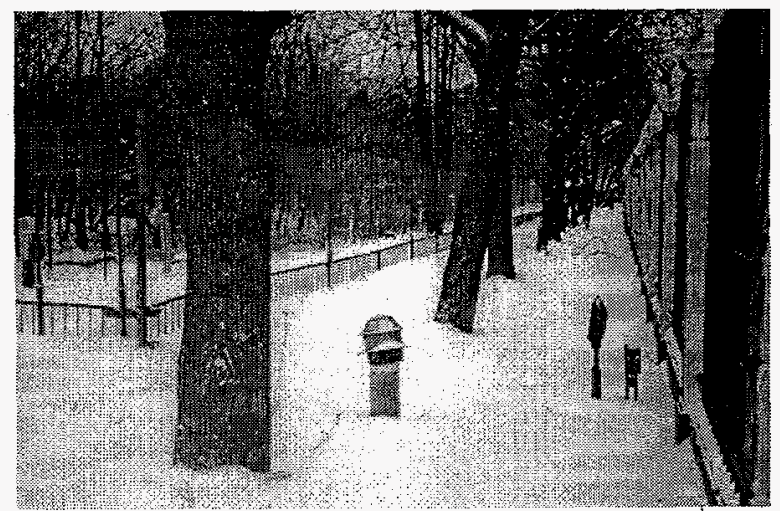

Figure 5. Established clear zone with trees.

\section{Barriers}

Site security relies in part on physical barriers, such as fences, to restrict movement around and within a facility. In conjunction with entry control systems, barriers can effectively maximize security. Barriers usually include a perimeter fence; a clear zone with sensors between the perimeter fence and the buildings; and sealed or otherwise secured doors, windows, and other points of potential access.

\section{Entry Control System}

Current entry control procedures at existing sites are guard-intensive and sometimes involve a badge exchange. Multiple key barriers, along with an exterior gate control system, constitute the physical aspect of entry and exit control. Key barriers are the entry control booths situated at the entrance/exit to the buildings and the entry control booths and access control systems for special access areas. Entry control booths include "man traps" which limit access to authorized personnel only. The booths can also include a variety of components such as card readers, keypads, and a weight check for entering and exiting a booth, metal detectors, and special nuclear material (SNM) detectors.

\section{Special Access Areas}

Special access areas are equipped with motion sensors, cameras and lights, interior and exterior keypads for access control, and access card readers. Often an intercom is included for communication between personnel within the room and security personnel. A "panic" button allows personnel to alert security and/or safety personnel to a serious situation.

\section{Sensors}

Several types of sensors at facilities provide detection of unauthorized activity as well as a routine monitoring capability. Intrusion detectors, installed at points closed to access, alert security personnel should a secured door, window, or other area be compromised.

Fencing and sensors secure the clear zone surrounding the building. Interior sensors monitor the special access rooms within the building. Security personnel can determine where movement is occurring within the confines of the facility and can assess whether it is authorized movement.

All sensors - interior and exterior-are networked electronically to an alarm communication and display system where video and alarm displays alert security personnel to the nature and status of an event. Metal detectors, which emit a very loud signal when metal is passed through them, are used for building entry and exit control. 
SNM radiation detectors are also part of the MPC\&A system design. These detectors are also connected to the central alarm station and produce an alarm signal when fissile material is detected. Once material is detected, the personnel booth will lock automatically.

\title{
The Alarm Assessment System
}

Sensors designed to detect specific types of activities augment the alarm assessment system that monitors both the interior and exterior of the facility.

CCTV cameras monitor the perimeter of the facility (clear zone) as well as certain areas within the building.

\section{CONCLUSION AND FUTURE EFFORTS}

Cooperative efforts between the US laboratories and their FSU counterparts have resulted in major enhancements to physical protection at various sites and advancement of other significant Government-to-Government projects. Many additional sites will benefit from similar improvements.

These physical protection efforts demonstrate that the FSU countries and the United States can indeed work together to implement real systems to protect nuclear materials. During the demonstration facility implementation projects, problems typical of coordinating efforts with new partners were encountered, solved, and noted. Future projects—projects that may range anywhere within the Government-to-Government program-will benefit from these "lessons learned."

\section{DISCLAIMER}

\begin{abstract}
This report was prepared as an account of work sponsored by an agency of the United States Government. Neither the United States Government nor any agency thereof, nor any of their employees, makes any warranty, express or implied, or assumes any legal liability or responsibility for the accuracy, completeness, or usefulness of any information, apparatus, product, or process disclosed, or represents that its use would not infringe privately owned rights. Reference herein to any specific commercial product, process, or service by trade name, trademark, manufacturer, or otherwise does not necessarily constitute or imply its endorsement, recommendation, or favoring by the United States Government or any agency thereof. The views and opinions of authors expressed herein do not necessarily state or reflect those of the United States Government or any agency thereof.
\end{abstract}

